\title{
CONDICIONANTES DA EXPORTAÇÃO BRASILEIRA DA PECUÁRIA DE LEITE ${ }^{1}$
}

Felipe Pinto da Silva²

José Eustáquio Ribeiro Vieira Filho ${ }^{3}$

Esta nota tem como objetivo apresentar a pesquisa no âmbito do termo de referência de concessão de bolsa referente ao projeto Rede de Pesquisa Integrada Ipea-Mapa, que criou o $\mathrm{NE}^{2} \mathrm{AGRO}$ Ipea-Mapa. O NE²AGRO tem o propósito de debater diversos temas sensíveis ao setor agropecuário. Como produto derivado, publicou-se um Texto para Discussão do Ipea com o título Avaliação de Impacto do Programa de Agricultura de Baixo Carbono no Brasil. Além disso, atividades de assessoramento, com dados estatísticos e informaçóes, são realizadas junto ao Mapa. Reunióes são feitas com o Observatório da Agropecuária Brasileira (dentro da Secretaria de Inovação, Desenvolvimento Rural e Irrigação) e há a criação de indicadores socioeconômicos da agricultura familiar (na Secretaria de Agricultura Familiar e Cooperativismo).

O próximo tema a ser aprofundado será a produção pecuária de leite no Brasil. A pecuária leiteira vinha ensaiando uma expansão em 2019, de acordo com a base de dados da Food and Agriculture Organization (FAO) ${ }^{4}$ a Food and Agriculture Organization Corporate Statistical Database (Faostat), acessada em 2020. A produção mundial de leite em 2019 chegou a 852 milhôes de toneladas, principalmente devido à expansão da produçáo de alguns países específicos, como Índia, Paquistão e Brasil. Essa dinâmica, no caso brasileiro, muito se deve ao aumento do estoque de vacas ordenhadas, facilitado pelo melhoramento das condiçóes de pastagens no referido ano. Em 2020, observou-se a conquista de novos mercados externos, celebrados por diversos acordos - há o desenrolar do acordo entre a União Europeia e o Mercado Comum do Sul (Mercosul), a abertura do mercado chinês para empresas produtoras de lácteos, a abertura do mercado egípcio, entre outros. Esse cenário contrasta com o longo contexto de crise vivido no passado pelo setor.

1. DOI: http://dx.doi.org/10.38116/brua24art17

2. Pesquisador do Núcleo de Estudos de Economia Agrícola (NE²AGRO) na Diretoria de Estudos e Políticas Regionais, Urbanas e Ambientais (Dirur) do Ipea. E-mail: <dasilva.felipe@outlook>.

3. Técnico de planejamento e pesquisa na Dirur/lpea; diretor de programa da Secretaria Executiva do Ministério da Agricultura, Pecuária e Abastecimento (Mapa); professor do Programa de Pós-Graduação em Agronegócio da Universidade de Brasília (Propaga/UnB) e em Economia da Universidade Federal de Viçosa (UFV). E-mail: <jose.vieira@ipea.gov.br>.

4. Disponível em: <http://www.fao.org/faostat/en/\#home>. Acesso em: 16 ago. 2020. 
Diversos estudos, como os de Nascimento et al. (2012) e Gonçalves et al. (2008), apontaram que a pecuária leiteira no Brasil, nos anos 2000, passou por várias mudanças produtivas, com o aumento da produtividade e da eficiência a partir do uso de diferentes critérios, que combinam volume e qualidade na produção de leite. Esses fatores, junto à desvalorizaçáo da moeda doméstica e à crise argentina de 2002, que impactou duramente a produção de leite do país, deram início à trajetória de crescimento da produção brasileira de leite até 2015 (Moraes e Bender Filho, 2017). O Brasil, entretanto, continuava dependente de importaçóes de produtos lácteos, já que ainda era incapaz de suprir a sua demanda interna.

A dependência do mercado externo se acentua principalmente depois de 2009, devido à redução da carga tributária e das tarifas alfandegárias dos itens lácteos da Argentina e do Uruguai, tornando os produtos desses países mais competitivos e criando incertezas para os produtores nacionais (Moraes e Bender Filho, 2017). No entanto, esses reverses não reverteram a trajetória ascendente da produção brasileira; isso só ocorreria em 2015, ano que marca o fim desses ganhos produtivos. Explica-se essa reversão de tendência devido a uma queda acentuada no preço real do leite (alcançando o menor valor no período de 2000 a 2014), a aumentos constantes nos custos de produção e a preços internacionais mais baixos (Carvalho et al., 2017). Essa crise se aprofunda em 2016, um ano de grande instabilidade nos preços relacionados a movimentos sazonais, agravada pela crise econômica no Brasil, que diminuiu o mercado interno. A produçáo brasileira de leite volta a aumentar levemente somente em 2018. Ainda assim, o Brasil é notoriamente um dos maiores produtores mundiais de leite, segundo a Faostat.

Em 2019, o Brasil apresenta um dos maiores crescimentos observados entre os maiores produtores no período 2018-2019 (3,5\%), abrigando um dos maiores rebanhos produtivos do mundo, atrás apenas da Índia. O total das exportaçóes brasileiras em 2019 foi de US \$ 37,58 milhões ( $5 \%$ da produção mundial), uma variação positiva de $0,5 \%$, em comparação com 2018, equivalendo a um total de 20.565,31 t (Comexstat, 2020).

Os principais destinos do leite brasileiro são Argélia, Emirados Árabes, Estados Unidos e Filipinas, representando, respectivamente, $23 \%, 11 \%, 8,1 \%$ e $7,8 \%$ do total exportado. Mesmo com esses números, o Brasil não se enquadra entre os maiores exportadores de lácteos, sendo um importador líquido. Segundo a Comexstat (2020), a balança comercial no setor é bastante desfavorável, apresentando um deficit de cerca US\$ 263 milhóes em 2019. Os produtos importados são de maior valor agregado, tendo como principal origem a Argentina e o Uruguai.

Vale salientar que, no primeiro semestre de 2019, a conjuntura externa foi muito positiva para o setor brasileiro. Pode-se elencar o preço internacional do litro de leite superior aos patamares históricos, o que implicou uma relaçáo favorável entre o preço do item e os custos com alimentação. Percebe-se que há uma reversão a partir de setembro, permanecendo dessa maneira até os dois primeiros meses de 2020 - mesmo assim, o setor fechou 2019 com um crescimento entre 2\% e 2,5\% (Carvalho, Rocha e Carneiro, 2020). Houve ainda uma seca no primeiro semestre na Oceania, principalmente na Austrália, limitando sua capacidade de exportação, já que a qualidade da pastagem diminuiu e houve escassez de água, contribuindo para a alta mundial de preços.

O terceiro trimestre de 2019 iniciou-se de maneira promissora. Houve, porém, uma reversão de tendência dos custos da produção de leite, potencializada pela crise provida pela pandemia da Covid-19 em 2020, compelindo o mundo a adotar políticas de isolamento 
social, com imenso impacto econômico e social. Essas mudanças impóem condicionantes ao mercado mundial de lácteos e um novo quadro de incertezas constrange a pecuária brasileira de leite. Entretanto, os principais condicionantes das exportaçóes devem estar claros, uma vez que poderão municiar os formadores de políticas públicas de informaçôes para a tomada de decisóes mais acertadas, principalmente no contexto atual de abertura de diversos mercados para os produtos lácteos brasileiros.

Nesse contexto, é nítida a necessidade de estudos que avaliem como problema o seguinte questionamento: quais são os principais condicionantes para o mercado internacional de lácteos e em que contexto se insere a economia brasileira? Sendo assim, o objetivo do estudo é analisar os fatores e/ou as variáveis determinantes da oferta de exportação da pecuária leiteira do Brasil. Dessa maneira, se buscará entender em que medida diversas variáveis influenciam a dinâmica produtiva. A principal hipótese de trabalho é que a renda, o preço, a distância geográfica, a taxa de câmbio e o indice de liberdade de negócios, entre outras características a serem elencadas, explicam a oferta de exportação praticada pela pecuária brasileira de leite. O método a ser trabalhado será a estimação de um modelo gravitacional. Espera-se, com os resultados, contribuir para a difusão e a consolidação de informaçóes relevantes à reformulação de políticas setoriais, bem como à promoção dos negócios nessa cadeia produtiva.

\section{REFERÊNCIAS}

CARVALHO, G. R. et al. Nota de conjuntura: leite e derivados. Juiz de Fora: Embrapa Gado de Leite, jan. 2017.

CARVALHO, G. R.; ROCHA, D. T. da; CARNEIRO, A. V. Indicadores: leite e derivados, v. 11, n. 100, 2020. Juiz de Fora: Embrapa Gado de Leite, 2020.

CILEITE - CENTRO DE INTELIGÊNCIA DO LEITE. Leite em números: produção de leite no Brasil. [s.l.]: CILeite, 2019. Disponível em: <https://bit.ly/2SGbwpn>. Acesso em: 16 ago. 2020.

FAO - FOOD AND AGRICULTURE ORGANIZATION. Overview of global dairy market developments in 2019. Dairy Market Review, Mar. 2020. Disponível em: <https://bit. ly/3w270A1>. Acesso em: 16 ago. 2020.

GONÇALVES, R. M. L. et al. Analysis of technical efficiency of milk-producing farms in Minas Gerais. Economia Aplicada, v. 12, n. 2, p. 321-335, 2008.

MORAES, B. M. M.; BENDER FILHO, R. Mercado brasileiro de lácteos: análise do impacto de políticas de estímulo à produção. Revista de Economia e Sociologia Rural, v. 55, n. 4, p. 783-800, out./dez. 2017.

NASCIMENTO, A. C. C. et al. Eficiência técnica da atividade leiteira em Minas Gerais: uma aplicação de regressão quantílica. Revista Brasileira de Zootecnia, v. 41, n. 3, p. 783-789, 2012.

SILVA, F. P. da; VIEIRA FILHO, J. E. R. Avaliaçáo de impacto do programa de agricultura de baixo carbono no Brasil. Brasília Ipea, 2020. (Texto para Discussão, n. 2568). 
